\title{
Synthesis of cast heat-resistant nickel aluminide alloys with tungsten boride
}

\author{
V. V. Gostishchev, I. A. Astapov ${ }^{\dagger}$ \\ †immaterial_khv@mail.ru
}

Institute of Material Studies of Far Eastern Branch of RAS, 153 Tikhookeanskaya St., 680042, Khabarovsk, Russia

Nickel aluminides of a composite structure reinforced with inclusions of refractory transition metal compounds possess big potential possibilities for a development of new materials with enhanced strength and thermal resistance. A variety of compositions of alloying systems allows one to obtain composites of different types with a set of improved characteristics. In the given work, experimental results on a production of materials based on intermetallic NiAl matrix with inclusions of tungsten boride are presented. Thermodynamic parameters of sequential reactions underlying the production of composites are determined and indicate on a high probability of an occurrence of a two-stage synthesis process. It is shown that the phase formation occurs as a result of thermally coupled exothermic reactions in $\mathrm{NiO}-\mathrm{Al}$ and $\mathrm{WO}_{3}-\mathrm{B}_{2} \mathrm{O}_{3}-\mathrm{Al}$ systems. It is established that to provide optimal conditions for the formation of intermetallic compounds $\mathrm{NiAl}, \mathrm{Ni}_{2} \mathrm{Al}_{3}$ it is necessary to have an excess of aluminum $(40 \%)$ in the initial charge. It has been shown that the introduction of inert additive $\mathrm{CaF}_{2}(15 \%)$ in a charge results to the maximum yield (about $85 \%$ ) of metal into an alloy. Increasing the concentration of $\mathrm{B}_{2} \mathrm{O}_{3}$ in the composition of the initial mixture from $\mathrm{WO}_{3}: \mathrm{B}_{2} \mathrm{O}_{3}=1: 0.15$ to $1: 0.45$ increases the volume fraction of tungsten boride content in the synthesized alloy. At the same time, lowering the temperature causes the formation of two intermetallic phases $\mathrm{NiAl}_{\text {and }} \mathrm{Ni}_{2} \mathrm{Al}_{3}$. $\mathrm{As}_{\mathrm{s}}$ the results of element analysis, X-ray diffraction and scanning electron microscopy show, the composite materials contain phases of $\mathrm{NiAl}$ and $\mathrm{Ni}_{2} \mathrm{Al}_{3}$ with inclusions of tungsten boride WB. The volume fraction of WB in NiAl-WB alloy amounted about $15 \%$ and in the alloy $\mathrm{NiAl}, \mathrm{Ni}_{2} \mathrm{Al}_{3}-\mathrm{WB}$ about 25\%. Microhardness of NiAl intermetallic matrix is 3,5-4,5 GPa. Microhardness of tungsten boride particles $(6,3-9,9 \mathrm{GPa})$ is below the theoretical value, which is not less than $20 \mathrm{GPa}$. This is associated with up to $5 \mathrm{wt}$. \% dissolution of nickel in this phase.

Keywords: nickel aluminide, tungsten boride, aluminothermy, phase composition, microhardness.

\section{Синтез литых термостойких сплавов алюминида никеля с боридом вольфрама}

\author{
Гостищев В.В., Астапов И. А. ${ }^{\dagger}$ \\ Институт материаловедения ХНЦ ДВО РАН, ул. Тихоокеанская 153, 680042, Хабаровск, Россия
}

Алюминиды никеля композитной структуры, упрочненные включениями тугоплавких соединений переходных металлов, обладают большими потенциальными возможностями в плане создания новых материалов с повышенной прочностью и термостойкостью. Разнообразие составов легирующих систем позволяет получать композиционные материалы разного типа с комплексом улучшенных характеристик. В работе представлены экспериментальные результаты по получению материалов на основе интерметаллидной матрицы NiAl с включениями борида вольфрама. Определены термодинамические параметры последовательных реакций, лежащих в основе получения композиционных материалов, которые указывают на высокую вероятность протекания двухстадийного процесса синтеза. Показано, что фазообразование происходит в результате термически сопряженных экзотермических реакций в системах $\mathrm{NiO}-\mathrm{Al}$ и $\mathrm{WO}_{3}-\mathrm{B}_{2} \mathrm{O}_{3}-\mathrm{Al}$. Установлено, что для создания оптимальных условий образования интерметаллидов $\mathrm{NiAl}$, $\mathrm{Ni}_{2} \mathrm{Al}_{3}$ необходимо обеспечить избыток алюминия (около 40\%) в составе исходной шихты. Показано, что введение инертных добавок $\mathrm{CaF}_{2}(15 \%)$ в шихту приводит к максимальному выходу (около 85\%) металла в сплав. Увеличение концентрации $\mathrm{B}_{2} \mathrm{O}_{3}$ в составе исходной шихты $\mathrm{WO}_{3}: \mathrm{B}_{2} \mathrm{O}_{3}=1: 0,15$ до 1:0,45 повышает объемное содержание борида вольфрама в синтезированном сплаве. Понижение температуры при этом служит причиной образования двух интерметаллидных фаз $\mathrm{NiAl}$ и $\mathrm{Ni}_{2} \mathrm{Al}_{3}$. По результатам элементного, рентгенофазового анализов и растровой электронной микроскопии композиционные материалы представлены фазами $\mathrm{NiAl}$ и $\mathrm{Ni}_{2} \mathrm{Al}_{3}$ с включениями борида вольфрама WB. Объемное содержание WB для сплава NiAl-WB составило 15\%, для сплава $\mathrm{NiAl}, \mathrm{Ni}_{2} \mathrm{Al}_{3}$-WB - 25\%. Микротвердость интерметаллидной матрицы NiAl составляет 3,5-4,5 ГПа. Микротвердость включений борида вольфрама WB (6,3 - 9,9 ГПа) ниже теоретической, которая не ниже 20 ГПа, что связано с растворением в этой фазе до $5 \%$ мас. никеля.

Ключевые слова: алюминид никеля, борид вольфрама, алюминотермия, фазовый состав, микротвердость. 


\section{1. Введение}

Интенсивное развитие современной техники выдвигает на первый план фундаментальные задачи создания материалов нового поколения с высоким комплексом свойств, способных обеспечить повышение ресурса работы деталей машин в экстремальных условиях эксплуатации. Большими потенциальными возможностями в плане создания материалов с уникальными свойствами обладают интерметаллидные сплавы системы $\mathrm{Ni}-\mathrm{Al}$. Эти материалы имеют высокие температуры плавления $\left(1395-1650^{\circ} \mathrm{C}\right)$, низкую плотность, повышенную жаростойкость. Важную роль в улучшении комплекса физико-механических свойств интерметаллидных сплавов играет формирование композитной структуры этих материалов из нескольких фаз. Алюминиды никеля с композитной структурой привлекают значительное внимание исследователей поскольку они обладают повышенной термической устойчивостью за счет вхождения в их структуру тугоплавких, термодинамически стабильных фаз внедрения. Основные принципы создания композиционных материалов, упрочненных более тугоплавкими чем матрица включениями изложены в работе [1]. При этом отмечено, что большое значение приобретает физико-химическая совместимость свойств компонентов композитов. Так, например, из-за интенсивного взаимодействия между матрицей и фазой внедрения возможна деградация структуры композитов, что может привести к ухудшению свойств материалов [2]. Вместе с тем, широкий выбор составов упрочняющих фаз (термодинамически устойчивых оксидов, боридов, карбидов металлов) обеспечивает возможность получения различных материалов с комплексом улучшенных характеристик. Так, например, получены алюминиды никеля системы $\mathrm{Ni}-\mathrm{Al}$, упрочненные включениями карбидов или боридов переходных металлов NiAl-NbC, NiAl-TiC, NiAl-TiB ${ }_{2}$, NiAl-MoB и др. [3,4]. Проблема получения алюминидов никеля и композитов на их основе решается в настоящее время путем использования, главным образом, традиционных литейных технологий и порошковой металлургии, которые отличаются многостадийностью технологических циклов, большими затратами [5 - 7]. Определенные перспективы для получения композиционных материалов представляет использование самораспространяющегося высокотемпературного синтеза, в частности СВСметаллургии. Высокая температура, развивающаяся в термитных процессах, труднодостигаемая обычным нагревом, дает возможность получать литые композиционные материалы по короткой схеме [8-10]. Ранее нами получены алюминиды никеля, упрочненные тугоплавкими соединениями: высшими боридами вольфрама и молибдена [11 - 12]. В развитие этих исследований изучение влияния условий синтеза на состав и структуру целевых продуктов с упрочняющей фазой иного состава представляет определенный интерес. В частности, целью настоящей работы является получение сплавов алюминида никеля с низшим боридом вольфрама методом СВС-металлургии».

\section{2. Методика и материалы}

В качестве исходных компонентов реакционных смесей использовали реагенты, чистота которых в мас.\% составляла: оксид никеля $\mathrm{NiO}-98,9$, оксид вольфрама $\mathrm{WO}_{3}-98,5$, оксид бора $-98,7$, порошок алюминия - 99,5 (средний размер частиц 50 мкм), кальций фтористый $\mathrm{CaF}_{2}$ марки «Ч». Фазовый состав определяли на дифрактометре ДРОН-7 ( $\mathrm{Cu}_{\mathrm{K} \alpha}$-излучение). Микротвердость исследовали на микротвердомере ПМТ-3М. Микроструктуру и элементный состав исследовали с помощью электронного микроскопа Jeol JCM-6000 c EDX-приставкой. Металлотермическую плавку проводили в жаропрочных металлических тиглях, футерованных огнеупорным материалом. В целом, процесс синтеза проводили по традиционной технологической схеме [13] Шихту готовили в виде двух слоев различного состава: в нижней части тигля располагали смесь реагентов для синтеза борида вольфрама, в верхней части помещали смесь для синтеза алюминида никеля. Тигель с шихтой из двух смесей, разделенных алюминиевой фольгой, помещали в реактор (рис. 1). Реактор герметизировали, заполняли аргоном. Металлотермическую реакцию локально инициировали электрозапалом сверху. Далее реакция протекала без внешнего подогрева. Образовавшийся расплав алюминида никеля прожигал алюминиевую фольгу, воспламенял нижнюю смесь реагентов и синтез борида вольфрама протекал совместно с расплавом интерметаллида. Это обуславливало перемешивание расплавов матричной и армирующей фазы целевого материала. В результате плавки образовывались продукты двух видов: металлическая фаза в форме компактного слитка и оксидная фаза, отчетливо разделенные на два слоя. Оксидная фаза в своем составе содержит, главным образом, $\mathrm{Al}_{2} \mathrm{O}_{3}, \mathrm{CaO}$.

\section{3. Результаты и обсуждение}

Процесс получения композиционного материала с определенной долей приближения может быть представлен в виде суммы частных реакций синтеза отдельных компонентов композита. На первом этапе происходит восстановление оксида никеля алюминием и формирование алюминида никеля по реакциям 1 и 2 (табл. 1).

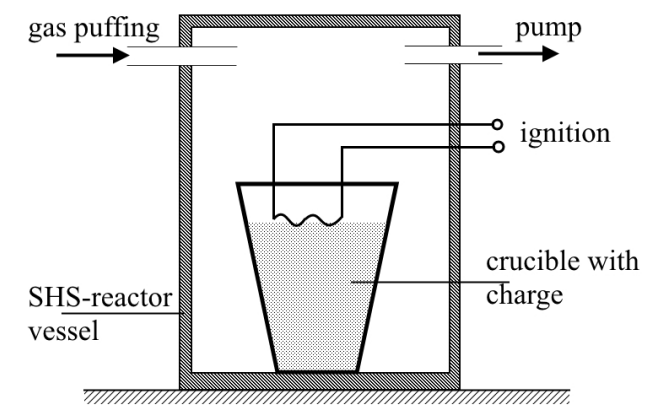

Рис. 1. Принципиальная схема СВС-реактора.

Fig. 1. Schematic diagram of the SHS reactor. 
На втором этапе синтез борида вольфрама протекает через стадию восстановления исходных реагентов таким образом, что оксид вольфрама и оксид бора восстанавливаются алюминием до элементов. В свою очередь вольфрам и бор взаимодействуют, образуя борид. Суммарно синтез борида может быть описан уравнением реакции 3 .

$$
\begin{aligned}
& 3 \mathrm{NiO}+2 \mathrm{Al}=3 \mathrm{Ni}+\mathrm{Al}_{2} \mathrm{O}_{3} \\
& \mathrm{Ni}+\mathrm{Al}=\mathrm{NiAl} \\
& 2 \mathrm{WO}_{3}+\mathrm{B}_{2} \mathrm{O}_{3}+6 \mathrm{Al}=2 \mathrm{WB}+3 \mathrm{Al}_{2} \mathrm{O}_{3}
\end{aligned}
$$

Принципиальную возможность получения композиционного материала оценивают на основании термодинамического анализа реакций синтеза отдельных компонентов. Результаты термодинамической оценки показывают, что вероятность прохождения реакций высока: изменению величины энергии Гиббса соответствуют большие отрицательные числовые значения, адиабатическая температура достаточна для распространения фронта горения (табл.1). Учитывая, что обе реакции термически сопряжены, температура, развивающаяся в алюминотермической системе в целом достаточна для ее расплавления и получения продукта в виде двухфазного высокотемпературного расплава, в котором металлическая фаза отделена от оксидной среды. Например, в системах $\mathrm{NiO}-\mathrm{Al}, \mathrm{WO}_{3}-\mathrm{Al}$ реальная температура достигает $2400-2500^{\circ} \mathrm{C}$.

Состав исходной шихты для синтеза композиционного материала устанавливали с учетом стехиометрического соотношения реагентов в реакциях синтеза. Очевидно, что для успешного формирования алюминида никеля и борида вольфрама необходимо обеспечить в составе шихты избыток алюминия. Эксперименты показали, что по мере увеличения избытка восстановителя в составе верхней части шихты значительное его количество переходит в сплав, не участвуя в восстановлении. Тем самым создаются условия благоприятные для синтеза алюминида никеля. При этом скорость горения металлотермической смеси прогрессивно ускоряется, не исключен вынос вещества из тигля. Разбавление реакционной системы путем введения инертных порошков $\mathrm{CaO}, \mathrm{CaF}_{2}$ приводит к снижению скорости горения. В тоже время инертные добавки снижают вязкость оксидной фазы и влияют на длительность высокотемпературной выдержки, что обеспечивает полноту выхода целевого продукта в металлический слиток. В результате конечным продуктом реакций является высокотемпературный расплав, в котором в следствие различия в плотностях, происходит разделение металлической и оксидной фаз. Охлажденные продукты синтеза отчетливо разделены на металлический и оксидный слой.

В ходе экспериментов синтезирован алюминид никеля легированный вольфрамом NiAl-W, а также композиционный материал на основе алюминида никеля и борида вольфрама состава NiAl-WB. Выход металлов в сплавы составляет 83-85\%масс. Следует заметить, что с изменением состава исходной шихты возможно получение материалов различного состава. Так увеличение концентрации $\mathrm{B}_{2} \mathrm{O}_{3}$ в составе исходной шихты приводит к повышению концентрации WB в целевом продукте при этом скорость реакции синтеза и температура расплава снижается, что может явиться причиной формирования двух интерметаллидных фаз $\mathrm{NiAl}$ и $\mathrm{Ni}_{2} \mathrm{Al}_{3}$. Результаты рентгенофазового и элементного анализов полученных материалов представлены в таблице 2 , и на рисунке 2.

Табл. 1. Термодинамические характеристики СВС-систем. Table 1. Thermodynamic characteristics of SHS-systems.

\begin{tabular}{|c|c|c|c|c|c|}
\hline \multirow{2}{*}{$N$} & $\begin{array}{c}\text { Реакционная } \\
\text { система } \\
\text { Reaction } \\
\text { system }\end{array}$ & $\begin{array}{c}\text { Целевой } \\
\text { продукт } \\
\text { End } \\
\text { product }\end{array}$ & $\begin{array}{c}\Delta \mathrm{G}_{1000 \mathrm{~K}}^{0} \\
\text { КДж/моль } \\
\Delta \mathrm{G}_{1000 \mathrm{~K}}^{0} \\
\mathrm{~kJ} / \mathrm{mol}\end{array}$ & $\begin{array}{c}T_{\text {ад }}, \mathrm{K} \\
T_{\text {ad’ }}, \mathrm{K}\end{array}$ & $\begin{array}{c}T_{\text {пл }}, \mathrm{K} \\
T_{\mathrm{m}}, \mathrm{K}\end{array}$ \\
\hline 1 & $\mathrm{NiO}+\mathrm{Al}$ & $\mathrm{Ni}$ & -944 & 3156 & 1726 \\
\hline 2 & $\mathrm{Ni}+\mathrm{Al}$ & $\mathrm{NiAl}$ & -105 & 1912 & 1911 \\
\hline 3 & $\mathrm{WO}_{3}+\mathrm{B}_{2} \mathrm{O}_{3}+\mathrm{Al}$ & $\mathrm{WB}$ & -2142 & 3354 & 3073 \\
\hline
\end{tabular}

\begin{tabular}{|c|c|c|c|c|c|}
\hline \multirow{2}{*}{ № } & \multirow{2}{*}{$\begin{array}{c}\text { Соотношение } \\
\text { основных } \\
\text { компонентов } \\
\text { Ratio of the main } \\
\text { components }\end{array}$} & \multicolumn{3}{|c|}{$\begin{array}{l}\text { Элемент, мас. \% } \\
\text { Element, mass. \% }\end{array}$} & \multirow{2}{*}{$\begin{array}{c}\text { Микротвердость, } \\
\text { ГПа } \\
\text { Microhardness, } \\
\text { GPa }\end{array}$} \\
\hline & & $\mathrm{Ni}$ & $\mathrm{Al}$ & $\mathrm{W}$ & \\
\hline 1 & $\begin{array}{c}\mathrm{NiO}: \mathrm{WO}_{3}: \mathrm{Al} \\
1: 0,1: 0,5\end{array}$ & 67,1 & 26,4 & 6,3 & $\begin{array}{c}\mathrm{NiAl}-3,5 \\
\mathrm{~W}-5,4\end{array}$ \\
\hline 2 & $\begin{array}{c}\mathrm{NiO}: \mathrm{Al} \\
1: 0.45 \\
\mathrm{WO}_{3}: \mathrm{B}_{2} \mathrm{O}_{3}: \mathrm{Al} \\
1: 0,15: 0,45\end{array}$ & 59,8 & 26,2 & 13,9 & $\begin{array}{l}\mathrm{NiAl}-4,3 \\
\mathrm{WB}-9,9\end{array}$ \\
\hline 3 & $\begin{array}{c}\mathrm{NiO}: \mathrm{Al} \\
1: 0,45 \\
\mathrm{WO}_{3}: \mathrm{B}_{2} \mathrm{O}_{3}: \mathrm{Al} \\
1: 0,45: 0,5\end{array}$ & 50,3 & 31,1 & 18,3 & $\begin{array}{c}\mathrm{NiAl}, \mathrm{Ni}_{2} \mathrm{Al}_{3}-4,5 \\
\mathrm{WB}-6,3\end{array}$ \\
\hline
\end{tabular}

Табл. 2. Состав и микротвердость композиционных материалов. Table 2. The composition and microhardness of composite materials.

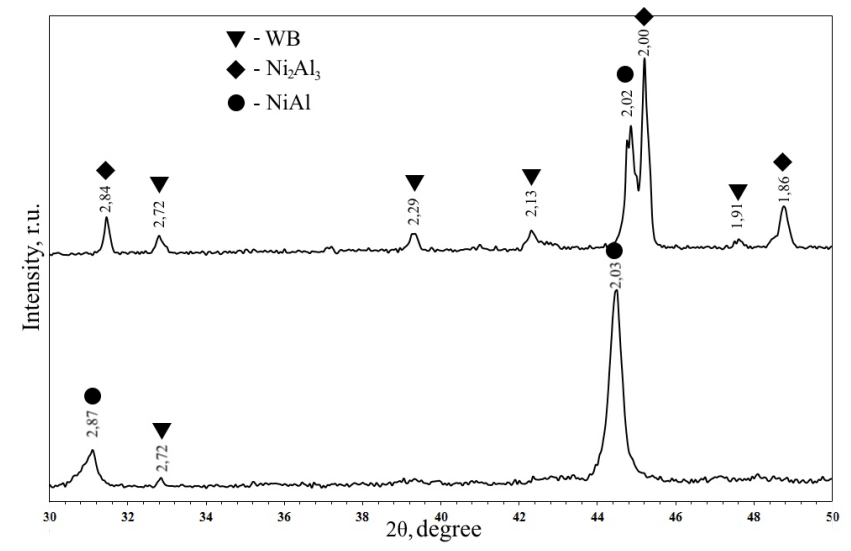

Рис. 2. Дифрактограммы сплавов NiAl- $\mathrm{Ni}_{2} \mathrm{Al}_{3}-\mathrm{WB}$ (a), NiAl-WB (b). Fig. 2. XRD-patterns alloys $\mathrm{NiAl}-\mathrm{Ni}_{2} \mathrm{Al}_{3}-\mathrm{WB}$ (a), NiAl-WB (b). 
Микроструктура сплавов представлена основными фазами $\mathrm{NiAl}$ и $\mathrm{Ni}_{2} \mathrm{Al}_{3}$ с отдельными включениями борида вольфрама (рис. 3), объемное содержание которых составляет 20,4-28,6\% (для сплава NiAl$\mathrm{Ni}_{2} \mathrm{Al}_{3}$-WB) и $12,9-17,7 \%$ (NiAl-WB), что согласуется с относительной интенсивностью характерных рефлексов на дифракгограммах. Экспериментально определено, что боридные включения в сплавах имеют значения микротвердости ниже теоретических. Рентгеноспектральный микроанализ указывает на растворение в этих фазах до 5 мас.\% никеля, что, вероятно, и приводит к снижению чисел твердости (табл. 2).

\section{4. Заключение}

Установлено, что последовательное проведение экзотермических реакций в системах $\mathrm{NiO}-\mathrm{Al}$ и $\mathrm{WO}_{3}-\mathrm{B}_{2} \mathrm{O}_{3}-\mathrm{Al}$ приводит к образованию литых сплавов на основе алюминидов никеля. Экспериментально найдено, что сплавы имеют композиционную структуру: в интерметаллидной матрице $\mathrm{NiAl}$ распределены включения борида вольфрама WB, объемное содержание которых составило 20,4-28,6 мас.\% (для сплава NiAl-Ni $\mathrm{Al}_{3}-\mathrm{WB}$ ) и 12,9-17,7 мас.\% (NiAl-WB). Микротведость боридной фазы приводит к увеличению общей твердости композитов, в тоже время экспериментально полученные данные для WB (6,3 - 9,9 ГПа) ниже теоретических из-за растворения никеля (до 5\%) в боридных включениях.

\section{Литература/References}

1. K.B. Povarova, A.A. Drozdov, N.K. Kazanskaya et al. Russ. Metall. 3 (2011), 209-220 (2011), Doi: 10.1134/S003602951103013X

2. K.B. Povarova, N.K. Kazanskaya, A.A. Drozdov, A.E. Morozov. Russ. Metall. 5 (2007), 380 - 386 (2007), Doi: 10.1134/S0036029507050060

3. V. N. Sanin, D. M. Ikornikov, V. I. Yukhvid, E. A. Levashov Centrifugal SHS-metallurgy of nickel aluminide based cast alloys, high-alloyed by boron. Non-ferrous metals. 11 (863), 83-89 (2014). (in Russian) [В.Н. Санин, Д.М. Икорников, В.И. Юхвид, Е.А. Левашов. Центробежная СВС-металлургия литых сплавов на основе алюминида никеля, высоколегированных бором. Цветные металлы. 11 (863), 83 - 89 (2014).]

4. J.A. Hawk, D.E. Alman. Wear. 1 (225-229), 544-556. (1999), Doi: 10.1016/S0043-1648 (99) 00006-X

5. R.D. Noebe, R. R. Bowman, M. V. Nathal. Physical Metallurgy and processing of Intermetallic Compounds. Book. (1996) 212 - 296, Doi: 10.1007/978-1-4613-1215-4

6. M.H. Enayati, F. Karimzadeh, S.Z. Anvari. J. Mater. Process. Technol. 1-3 (200) 312-315 (2008), Doi: 10.1016/j.jmatprotec.2007.09.023

7. O.A. Skachkov, K.B. Povarova, A.A. Drozdov, A.E. Morozov. Russ. Metall. 5 (2012), 431 - 434 (2012), Doi: $10.1134 /$ S0036029512050138

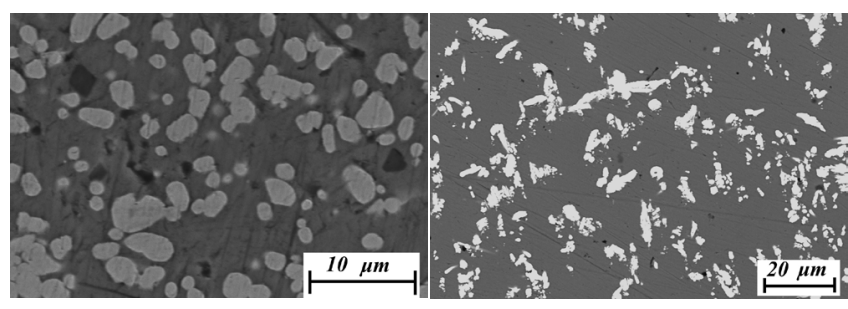

a

b

Рис. 3. РЭМ-изображения синтезированных сплавов: $\mathrm{NiAl}-\mathrm{Ni}_{2} \mathrm{Al}_{3}-\mathrm{WB}(\mathrm{a}), \mathrm{NiAl}-\mathrm{WB}(\mathrm{b})$.

Fig. 3 SEM images of the synthesized alloys: NiAl- $\mathrm{Ni}_{2} \mathrm{Al}_{3}-\mathrm{WB}$ (a), NiAl-WB (b).

8. V.I. Yukhvid High-temperature liquid-phase SHS processes: new trends and challenges. Nonferrous metallurgy. 5, $62-78$ (2006) [В.И. Юхвид Высокотемпературные жидкофазные СВС-процессы: новые направления и задачи. Цветная металлургия. 5, 62 - 78 (2006).]

9. A. G. Merzhanov, V.I. Yukhvid, I. P Borovinskaya. SHS cast refractory inorganic compounds. Reports of the Academy of Sciences of the USSR. 1 (255), 120-124 (1980) [А.Г. Мержанов, В.И. Юхвид, И.П. Боровинс кая И.П. Самораспространяющийся высокотемпературный синтез литых тугоплавких неорганических соединений // Доклады АН СССР. 1 (255), 120 - 124 (1980).]

10. V. N. Sanin, D. E. Andreev, V. I. Yukhvid. Russian Journal of Non-Ferrous Metals. 3 (54), $274-279$ (2013), Doi: $10.3103 /$ S1067821213030152

11. Gostishchev V. V, Astapov I. A., Medneva A. V. Synthesis of composites based on nickel aluminide and molybdenum borides. Voprosy materialovedeniya. 4(48). 45-50 (2015) (in Russian) [Гостищев В.В., Астапов И.А., Меднева А. В. Получение композитов на основе алюминида никеля и боридов молибдена. Вопросы материаловедения. 4(48). 45 - 50 (2015)]

12. GostishchevV.V,AstapovI. A., KhimukhinS. N.Poluchenie nikel-alyuminievyx splavov s boridami volframa i molibdena metodom SVS-metallurgii. Materialovedenie. 12. 25-29 (2016) (in Russian) [Гостищев. В. В., Астапов И.А., Химухин С.Н. Получение никель-алюминиевых сплавов с боридами вольфрама и молибдена методом СВС-металлургии. Материаловедение. 12. $25-29$ (2016)]

13. Levashov E.A., Rogachev A.S., Kurbatkina V.V., Maskimov Ju.M., Juhvid V.I. Perspektivnye materialy i tehnologii samorasprostranjajushhegosja vysokotemperaturnogo sinteza. Uchebnoe posobie. Moscow, NUST MISIS, (2011). 377 p. (in Russian) [Левашов Е.А., Рогачев А.С., Курбаткина В.В., Маскимов Ю.М., Юхвид В.И. Перспективные материалы и технологии самораспространяющегося высокотемпературного синтеза. Учебное пособие. Москва. Изд. дом МИСиС. (2011). 377 с.] 